\title{
Definitive radiotherapy for uterine cervix cancer: long term results for patients treated in the period from 1998 till 2002 at the Institute of Oncology Ljubljana
}

\author{
Helena Barbara Zobec Logar, Barbara Segedin, Robert Hudej, Primoz Petric \\ Department of Radiotherapy, Institute of Oncology Ljubljana, Zaloška 2, 1000 Ljubljana, Slovenia;
}

Radiol Oncol 2013; 47(3): 280-288.

Received 26 December 2012

Accepted 24 January 2013

Correspondence to: Helena Barbara Zobec Logar, MD, MSc, Department of Radiotherapy, Institute of Oncology Ljubljana, Zaloška 2, 1000 Ljubljana, Slovenia. Phone: +386 15879 204; Fax: +386 15879 400; E-Mail: hlogar@onko-i.si

Disclosure: No potential conflicts of interest were disclosed.

\begin{abstract}
Background. The aim of this retrospective study was to analyse results of the two-dimensional (2D) uterine cervix cancer treatment at the Institute of Oncology Ljubljana from 1998 till 2002, before the three-dimensional (3D) approach was introduced in our clinical practice.

Methods. Ninety-eight patients with the following FIGO stage distribution were analysed: $10 \%$ IB, $7 \%$ IIA, 37\% IIB, 4\% IIIA and $42 \%$ IIIB. The influence of age, haemoglobin level, histology, grade, stage, lymph node status, cumulative point A dose, and an overall treatment time on the survival and local control (LC) were evaluated. Acute and late side effects were assessed.

Results. Five and 8-year overall survival (OS), disease specific survival (DSS) and LC rate were as follows: $47.2 \%$ and $43.0 \%, 54.7 \%$ and $53.4 \%, 74.9 \%$ and $72.5 \%$, respectively. Point A dose and histology of the tumour influenced OS, positive lymph nodes DSS and point A dose LC rate. Probability of grade three and four late complications in the first five years was $7.1 \%$ for gastrointestinal tract and $3.3 \%$ for genitourinary system and vagina.

Conclusions. Point A dose was independent predictor of OS and LC rate, lymph node status predicted DSS, while histology of the tumour influenced OS.
\end{abstract}

Key words: uterine cervix cancer; external beam radiotherapy; brachytherapy

\section{Introduction}

Brachytherapy (BT) in combination with external beam radiotherapy (EBRT) and chemotherapy plays a key role in the definitive treatment of locally advanced uterine cervix cancer. ${ }^{1-6}$

In the field of EBRT, sectional imaging has been widely implemented into the treatment planning process during recent decades. Three-dimensional (3D) conformal computed tomography (CT) based EBRT, employing megavoltage linear accelerators and customized shielding, nowadays represents a generally accepted approach to irradiation in the majority of tumours. Modern EBRT techniques, including intensity modulated radiotherapy and emerging new approaches, allow for increased dose conformity and a tight control over dose distribution in the irradiated tissues.

However, as far as gynaecological BT is concerned, treatment planning in the majority of institutions worldwide is currently still based on a twodimensional (2D) approach, utilizing a geometrical system of points, defined on two orthogonal pelvic radiographs with the applicator in place. ${ }^{6-11}$ In cervix cancer $B T$, this approach refers mainly to dose prescription at point $\mathrm{A}^{6-9}$, while the dose to organs at risk (OAR) is most often reported at points as suggested by the International Commission on Radiation units and measurements (ICRU) Report 38 or their alternatives. ${ }^{78}$ Due to the absence of 
visual information on spatial interrelations between the applicator, the target volume and organs at risk, which differ from patient to patient, application to application and even within one application, the 2D approach is characterized by uncertainties regarding dose delivery to the irradiated tissues. In addition, the definition of pointrelated target and normal tissue dose constraints is controversial due to the steep dose gradient, dose inhomogeneity and non-contiguous high dose regions over the irradiated volume. ${ }^{7-9}$ It is therefore clearly more appropriate and reliable to correlate the effects of radiation on tissues with doses, absorbed in certain volumes, rather than at specific points. ${ }^{12-18}$ These correlations have been enabled by introduction of 3D sectional imaging into BT treatment planning. ${ }^{12-14,17}$

Nevertheless, a large amount of evidence that supports the correlation between conventional radiography based point doses and the clinical outcome exists. $7,8,12-14,17-25$

At the Institute of Oncology Ljubljana we have been performing $2 \mathrm{D}$ radiography based uterine cervix cancer BT until 2006. Subsequently, 3D MRI assisted BT treatment planning has been systematically implemented and currently represents our standard treatment approach. ${ }^{26,27}$ When introducing a new method of planning, prescribing, recording and reporting the treatment, it is essential to have a thorough knowledge and understanding of existent traditional institutional techniques. Only by a careful analysis of long standing experience and by linking conventional dosimetric and clinical parameters to the sectional imaging based data, it is possible to avoid potentially hazardous deviations from 2D approach and to fully exploit the benefits of 3D sectional imaging based BT.

This report summarizes a single institutional experience with $2 \mathrm{D}$ radiography based treatment planning in uterine cervix cancer radiotherapy in a time period between 1998 and 2002. After 2002, 3D conformal CT-based EBRT was systematically introduced in our clinical practice.

\section{Patients and methods}

\section{Patients and tumours}

Ninety-eight patients with histologically confirmed uterine cervix cancer and complete medical records that were treated with curative intent with radiotherapy +/- chemotherapy at the Institute of Oncology Ljubljana in the period from January 1998 till December 2002 were enrolled and retrospec- tively analysed. The investigators followed recommendations of the Helsinki Declaration (1964, with later amendments) and of the European Council Convention on Protection of Human Rights in BioMedicine (Oviedo 1997).

Mean patient age was 60.1 (23 to 85 ) years. Pretreatment patient work-up consisted of gynaecological examination (all patients), chest radiography $(98 \%)$, cystoscopy $(42 \%)$, proctoscopy $(32 \%)$, intravenous urography (19\%), abdominal ultrasound $(45 \%)$ and computed tomography (17\%). Each patient was examined by at least three independent examiners, two gynaecologists and one radiation oncologist.

FIGO stage distribution was as follows: $10 \% \mathrm{IB}$, $7 \%$ IIA, 37\% IIB, $4 \%$ IIIA and $42 \%$ IIIB.

The predominant histological type was squamous cell carcinoma (SCC), representing $92 \%$ of all tumours, followed by adenocarcinoma (3\%) and other histologies (5\%). The tumours were well, moderately and poorly differentiated in 10, 25 and $30 \%$, respectively.

\section{Treatment}

The mean interval between the first presentation and the beginning of the treatment was 24 days (range 1-60). All patients were treated with a combination of EBRT +/- concurrent chemotherapy and BT. Mean overall treatment time was 52 days \pm 11 days.

EBRT was delivered following conventional radiography-based simulation at a 5-15 MV linear accelerator in $99 \%$ and at a Cobalt-60 device in 1\% of patients. A mean dose applied via pelvic fields was 40 Gy (20-60 Gy) (2 Gy per fraction, five fractions weekly). A four field technique was applied in 10\% and the technique of two opposite fields in $90 \%$.

Paraaortic radiotherapy (mean dose: 32 Gy; range: $20-40 \mathrm{~Gy}$ ) was carried out in four (4.1\%) patients with positive paraaortic $(\mathrm{n}=3)$ and interiliac $(\mathrm{n}=1)$ lymph nodes, as determined by ultrasound or CT.

Six $(6.0 \%)$ patients received chemotherapy (weekly cisplatin, $40 \mathrm{mg} / \mathrm{m}^{2}$ ) concurrent with EBRT.

Following completion of EBRT, low dose rate (LDR) brachytherapy with ${ }^{137} \mathrm{Cs}$ source was applied. A Henschke-type metallic applicator consisting of an intrauterine tandem and a pair of vaginal ovoids was utilized. In 95 (97\%) patients, one insertion was performed. Three $(3 \%)$ patients received two insertions after an interval from one to four weeks. Following insertion, two orthogonal pel- 
vic radiographs with the applicator in place were taken. A mean nominal dose of 25 Gy (range 12-36 Gy) was prescribed to point A. Treatment planning was carried out using our in-house developed software application, and was based on the information obtained from the orthogonal radiography. Nominal doses at the ICRU-points for the rectum (ICRU-R) and bladder (ICRU-B) were calculated and recorded. ${ }^{8}$

For the purpose of adding doses from EBRT and BT, it was assumed that the EBRT dose to Manchester point A, point B (3 cm lateral to point A) and to the ICRU points for the bladder and rectum equalled the prescribed EBRT dose. In this study, at time of BT, the rate of dose delivery by the ${ }^{137} \mathrm{C}$ s source was not equal to the reference dose rate $(0.5 \mathrm{~Gy} / \mathrm{h})$. In addition, the dose rate was not equal for all patients due to a gradual decrease of ${ }^{137} \mathrm{C}$ s source activity with time. Therefore, to enable meaningful comparisons of individual treatments, cumulative (EBRT + BT) biologically equivalent doses (EQD2) to the Manchester point A, point B and ICRU points for the bladder and rectum were calculated using the linear quadratic model (reference EBRT dose per fraction $=2 \mathrm{~Gy}$, reference BT dose rate $=0.5 \mathrm{~Gy} / \mathrm{h}, \alpha / \beta$ for the tumour $=10 \mathrm{~Gy}$, $\alpha / \beta$ for the organs at risk $=3 \mathrm{~Gy}$, sublethal damage repair half time $=1.5 \mathrm{~h}) .{ }^{7}$ During treatment planning, we aimed at keeping the biological equivalent dose at the ICRU-R and ICRU-B points below our departmental limits of $70 \mathrm{~Gy}$. No attempt was made to assess the dose to other organs at risk (i.e. sigmoid colon, small bowel and vagina).

\section{Follow up}

Acute treatment side effects were assessed during the treatment and recorded descriptively in the patient chart. For the purpose of this study the Radiation Therapy Oncology Group (RTOG) criteria $^{28}$ were employed in an attempt to retrospectively assign corresponding RTOG toxicity levels to individual cases, according to the descriptions in the patient charts. The haemoglobin level was recorded before, during and after the treatment.

Chronic side effects were evaluated the time of each follow-up visit after the treatment and are reported here according to LENT-SOMA scale. ${ }^{29}$ Follow-up investigations were performed respecting our institutional guidelines. ${ }^{30-32}$

Overall survival (OS), disease specific survival (DSS) and local control (LC) actuarial rates were defined as the period from the date of biopsy to the date of death, disease related death and first docu- mented evidence of disease progression or recurrent tumour in true pelvis, respectively.

\section{Statistical analysis}

The data were analysed using SPSS 13.0 statistical software package (version 13 for Windows, Copyright $($ SPSS Inc., Chicago, Illinois). All statistical tests were double-sided; differences at $\mathrm{p}<0.05$ were considered statistically significant.

T-test was used to assess the statistical significance of differences between values of continuous variables. Kaplan-Meier method was applied to calculate actuarial survival and LC rates. Patients without recurrence were censored at time of the last follow-up, visit or death. Surviving patients were censored at time of the last follow-up. Frequencies of different grades of acute and chronic toxicity were calculated. Using the univariate statistical analysis, the influence of FIGO stage, age, nodal status, haemoglobin level, histological type, grade, cumulative EQD2 at point A and overall treatment time on the survival and LC rates were assessed by using a log-rank test. Variables such as age, haemoglobin level and overall treatment time were analysed as quantitative variables using arbitrary cut points $(\mathrm{Hb}<100 \mathrm{~g} / \mathrm{l}, \mathrm{Hb} \geq 100 \mathrm{~g} / \mathrm{l}$, overall treatment time $\leq 50$ days and $>50$ days, age $<60$, $\geq 60$ years). A multivariate analysis, based on the Cox form of the proportional hazards regression model, was performed to test possible predictive variables (method enters probability to enter 0.05, probability to remove 0.1 ).

\section{Results}

\section{Dosimetric data}

Cumulative (EBRT + BT) EQD2 at Manchester point A, B, ICRU-R and ICRU-B points are presented in Table 1 . There were no statistically significant differences in the mean EQD2 delivered at point A between patients with different FIGO stages (Figure 1). The point A EQD2 was below 60 Gy in $26.0 \%$, between 60 and 80 Gy in $70.0 \%$ and above $80 \mathrm{~Gy}$ in $5.0 \%$ of patients, respectively. The mean cumulative EQD2 at ICRU-B and ICRU-R point was 56.9 Gy (range 37.5-79.3) and 62.2 (range 38.3$82.5)$, respectively.

\section{Survival and local control}

The mean follow-up was 77 months (range 2-162 months). The 5-year OS and DSS rates were $47.2 \%$ 
TABLE 1. Cumulative (EBRT + BT) biologically equivalent doses (EQD2) at Manchester point A, point B and ICRU points for the bladder and rectum (ICRU-B and ICRU-R)

\begin{tabular}{ll}
\hline Point & EQD2 mean [range] (GY) \\
\hline A & $66.5[38.7-93.6]$ \\
B & $60.1[24.2-69.0]$ \\
ICRU-B & $56.9[37.5-79.3]$ \\
ICRU-R & $62.2[38.3-82.5]$ \\
\hline
\end{tabular}

and $54.7 \%$. As expected, the 5-year OS rate was significantly lower for metastatic disease (patients with positive paraaortic lymph nodes and distant relapse), as for nonmetastatic disease $(5.6 \%$ versus $54.7 \%, p=0.000)$. OS, DSS and LC rates for different FIGO stages at five end eight years are represented in Figures 2 to 4.

The overall LC rate at five years was $74.9 \%$. Six out of 98 patients $(6 \%)$ had residual disease at the first follow-up ( 2 stage IIB, 1 stage IIIA and 3 stage IIIB). Two patients developed distant metastases during the treatment (both stage IIIB). All of these patients died.

Twenty-seven $(28.0 \%)$ out of 98 patients developed a relapse, $11(11 \%)$ in pelvis, $15(15 \%)$ at distant sites and one (1\%) in pelvis and distant sites simultaneously. A central pelvic relapse was observed in eight (8\%) and a side wall relapse in three patients $(3 \%)$. Seven patients were secondarily treated with salvage surgery or radiotherapy, but none of them survived.

The first sites of distant relapse were paraaortic lymph nodes in six, lung in four, liver in three, supraclavicular nodes in two and bone in one patient. For patterns of recurrence see Table 2 .

The overall LC rate at eight years was $72.5 \%$. After eight years of the follow up one more stage IIA patient developed a central pelvic relapse. One stage IIIB patient developed a distant relapse (paraaortic lymph nodes and lung) after 9.2 years of the follow up.

All three patients with positive paraaortic lymph nodes died within 14 months from the time of diagnosis. The only patient with enlarged lymph nodes, who survived to the time of analysis, was the one with positive interiliacal nodes.

Point A dose had an important role in LC and survival. The 5-year OS rate was $32.1 \%$ if the dose to point $\mathrm{A}$ was less than $65 \mathrm{~Gy}$ and $56.3 \%$ when point A dose was 65 Gy or more $(p=0.005)$. The same was true for DSS and LC. The 5-year DSS was $48.4 \%$ for the lower dose and $69.1 \%$ for the higher

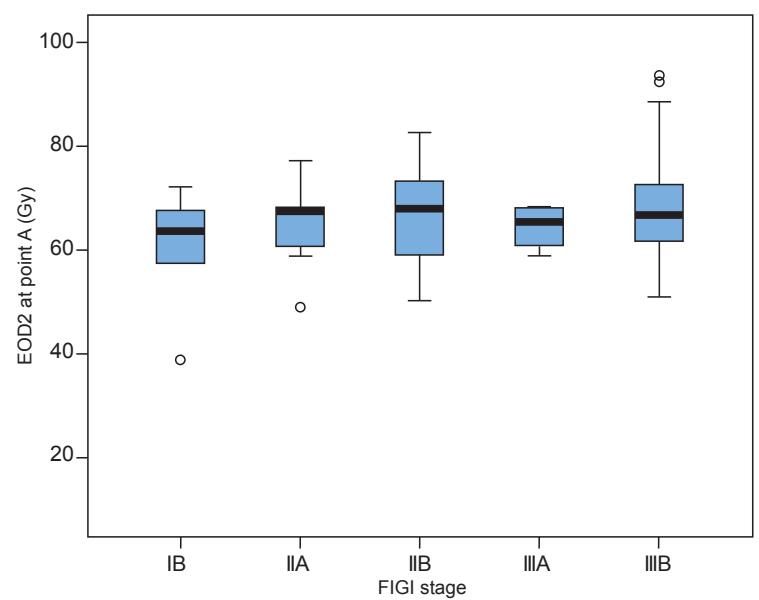

FIGURE 1. Cumulative EQD2 delivered at point $A$ in different FIGO stages. Black horizontal lines represent mean values of EQD2 for each FIGO stage. The height of the box is equal to the interquartile range (IQR), which is the range within which the middle $50 \%$ of the ranked data are found. The whiskers indicate the range of the data. Dots represent extreme values.

dose $(p=0.08)$. LC rate was $40.2 \%$ for the lower dose versus $84.0 \%$ for the higher dose $(p=0.03)$. The proportion of local recurrences was lower with a higher point A dose (Figure 5). Above 75 Gy no local recurrence was registered.

The histological type of the tumour influenced OS, which was better for SCC than for adenocarcinoma or adenosquamous carcinoma (46.3 vs. $0 \%$; $\mathrm{p} \leq$ 0.005). Positive lymph nodes were associated

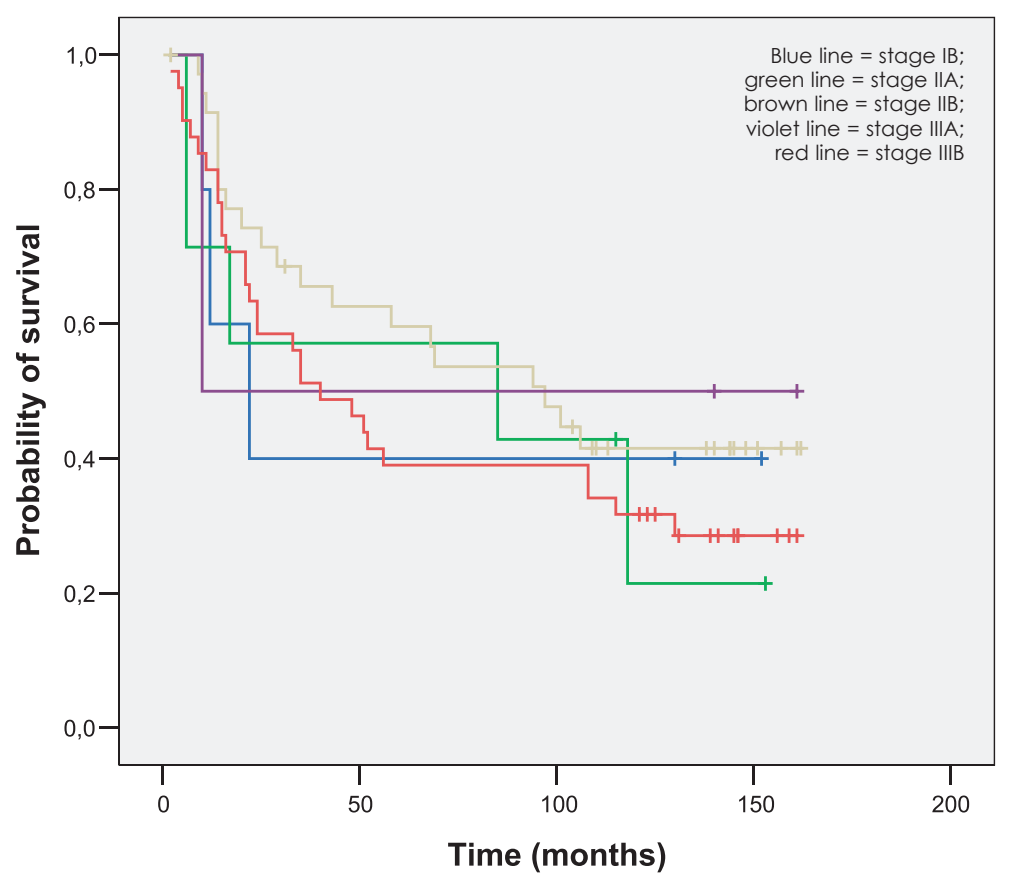

FIGURE 2. Overall survival according to FIGO stage. 


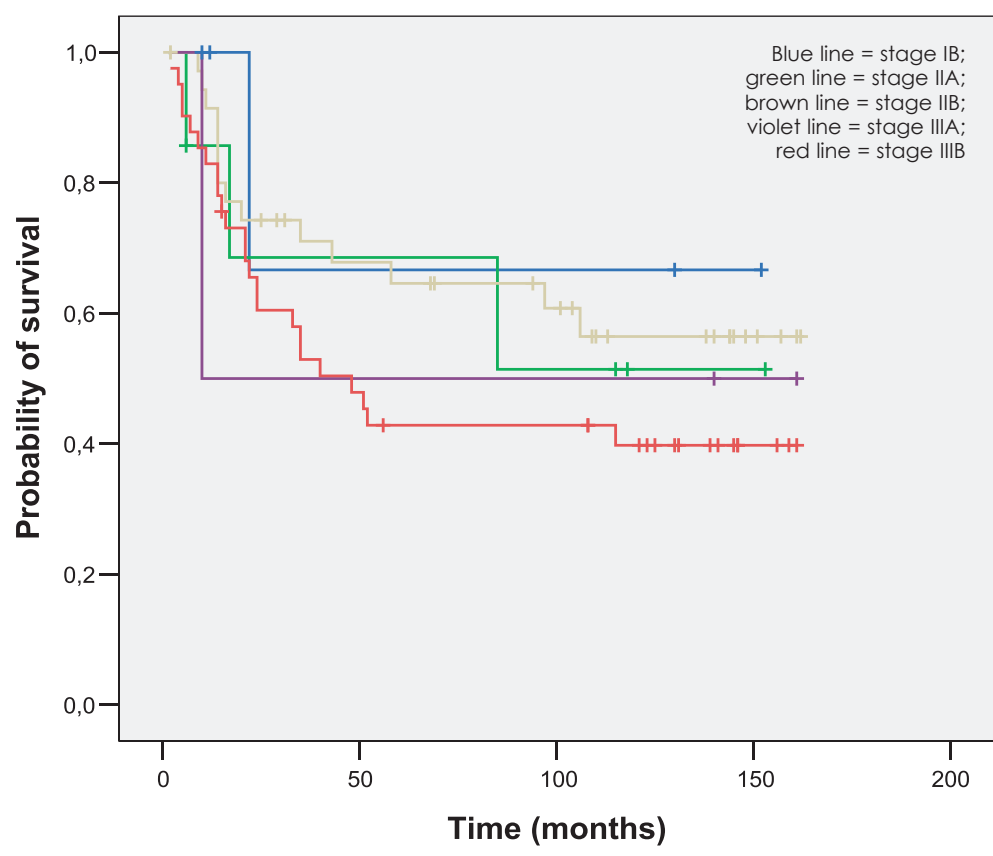

FIGURE 3. Disease specific survival according to FIGO stage.

with a drop in 5-year DSS. If the lymph nodes were negative DSS was $64.5 \%$, vs. $18.8 \%$ in case of positive iliac or paraaortic lymph nodes $(p=0.01)$.

Variables such as age, grade, stage, haemoglobin level and overall treatment time didn't influence survival and LC.

In the multivariate analysis, point A dose retained its independent prognostic value for the OS $(\mathrm{p}=0.03$, hazard ratio $(\mathrm{HR})=0.5$, confidence inter$\operatorname{val}(\mathrm{CI})=0.3-0.9)$.

\section{Acute and late side effects}

Acute gastrointestinal toxicity was reported in twelve $(12.2 \%)$ patients. In general it was mild, with grade 1, 2 and 3 proctitis appearing in eight
$(8.3 \%)$ two $(2.0 \%)$ and two $(2.0 \%)$ patients, respectively. Acute urinary side effects were reported only in four $(4.0 \%)$ patients, grade 1 in two $(2.0 \%)$, and grade 3 in one $(1.0 \%)$ patient. Only one patient $(1.0 \%)$ experienced grade 4 acute toxicity.

The mean initial haemoglobin level was 120 (82152) $\mathrm{g} / \mathrm{l}$, fell to 111 (59-150) g/l during the treatment and rose again after the treatment to a mean level of 120 (83-155) g/l in the next four months. The difference between initial and nadir haemoglobin levels was statistically significant $(p<0.005)$. Transfusion received $14.9 \%$ of the patients and erythropoietin received $3.1 \%$ of the patients on chemotherapy. There was no statistically significant difference in survival and LC in patients with a low haemoglobin level.

Chronic gastrointestinal side effects were reported by fifteen $(15.3 \%)$ patients with eight $(8.2 \%)$ experiencing grade 1 , one $(1.0 \%)$ grade 2 , two $(2.0 \%)$ grade 3 and four $(4.1 \%)$ grade 4 late gastrointestinal toxicity. One patient developed a rectovaginal fistula, two patients developed ileus, anus praeter was formed in one patient.

Ten $(10.2 \%)$ patients experienced late genitourinary tract toxicity: four (4.1\%) grade 1 , four $(4.1 \%)$ grade 2 and two $(2.0 \%)$ grade 4 . Incontinence, haematuria, rise of serum creatinine level and mild hydronephrosis were the most common chronic genitourinary side effects. Rise of creatinine level and mild hydronephrosis developed independently of chemotherapy.

Twelve (12.2\%) patients experienced late vaginal toxicity, five $(5.1 \%)$ grade 1 , five $(5.1 \%)$ grade 2 , one $(1.0 \%)$ grade 3 and one $(1.0 \%)$ grade 4 . Vaginal stenosis represented the most commonly reported complication.

The probability of developing late side effects of any grade in first five years was $16.6 \%$ for gastrointestinal tract, $15.7 \%$ for genitourinary system and $22.3 \%$ for the vagina. The probability of grade three and four late side effects in the first five years was

TABLE 2. Pattern of progression and relapse according to FIGO stage. The numbers represent numbers of patients which equals to per cent of patients

\begin{tabular}{|c|c|c|c|c|c|c|}
\hline Stage & IB & IIA & IIB & IIIA & IIIB & Total \\
\hline Total number & 10 & 7 & 36 & 4 & 41 & 98 \\
\hline Local progression & & & 2 & 1 & 3 & 6 \\
\hline Distant progression & & & & & 2 & 2 \\
\hline Pelvic relapse (central/ side wall) & & $1(1 / 0)$ & $4(3 / 1)$ & $1(1 / 0)$ & $5(3 / 2)$ & $11(8 / 3)$ \\
\hline Distant relapse & 2 & 1 & 4 & 1 & 7 & 15 \\
\hline Overall failure & 2 & 2 & 11 & 3 & 17 & 35 \\
\hline No evidence of disease & 8 & 5 & 25 & 1 & 24 & 63 \\
\hline
\end{tabular}


7.1\% for gastrointestinal tract and 3.3\% for genitourinary system and vagina.

The mean interval before developing the late complication of any grade was 27.6 months (range 6-96 months) for gastrointestinal, 28.7 months (range 3-65 months) for genitourinary and 27.2 months (range 5-53 months) for late vaginal squeal. The mean interval before developing a serious late complication (grade 3 and 4) was 26.5 (range 3-94 months) for gastrointestinal tract, 21.5 months (range 16-27) for genitourinary tract and 21.5 months (range 16-27 months) for the vaginal complications.

\section{Discussion}

In the present study we evaluated historical data of combined EBRT and 2D LDR BT in the treatment of uterine cervix cancer. All the data were collected in a retrospective manner and only patients who received combined EBRT and BT treatment were included. There was no stage IVA disease patient treated with a combined therapy in the study. The weakness of the study was also uneven distribution of patients in different FIGO stages, especially a low number of stage IIA and IIIA patients, which was less than $10 \%$.

The 5-year OS and DSS rates for all 98 patients were $47.2 \%$ and $54.7 \%$. OS rate for stage IB was only $40.0 \%$, which was lower than expected and lower than the reported survival rates for more advanced disease. ${ }^{33-39}$ Mean age of patients with stage IB disease was higher when compared to the whole group $(68.8 \pm 13.4$ years compared to $60.1 \pm 14.2$ years), so other age related comorbidity factors may have caused lower OS rate. In five out of ten patients in stage IB the death was not associated with primary disease, one patient died of breast cancer, two of metastatic disease due to uterine cervix cancer.

Five-year OS and DSS rates for stage IIA were $44.0 \%$ and $55.6 \%$, with LC rate of $66.7 \%$. Low LC rate $(50.0 \%)$ was also observed in stage IIIA with DSS rate of $50.0 \%$. The Vienna group reported $100.0 \%$ and $52.7 \%$ pelvic control rate for stage IIA and IIIA at three years, respectively, while Perez et al. reported a pelvic failure rate of $0-28 \%$ in stage IIA disease and $32-50 \%$ in stage III disease at ten years. ${ }^{35,38}$ Barillot et al. reported $14.5 \%$ 5-year pelvic failure rate in stage IIA disease and $40 \%$ in stage IIIA disease. ${ }^{39}$ We believe that rather high pelvic failure rates in these stages $(33.3 \%$ in stage IIA, $50.0 \%$ in stage IIIA), were mainly due to the exten-

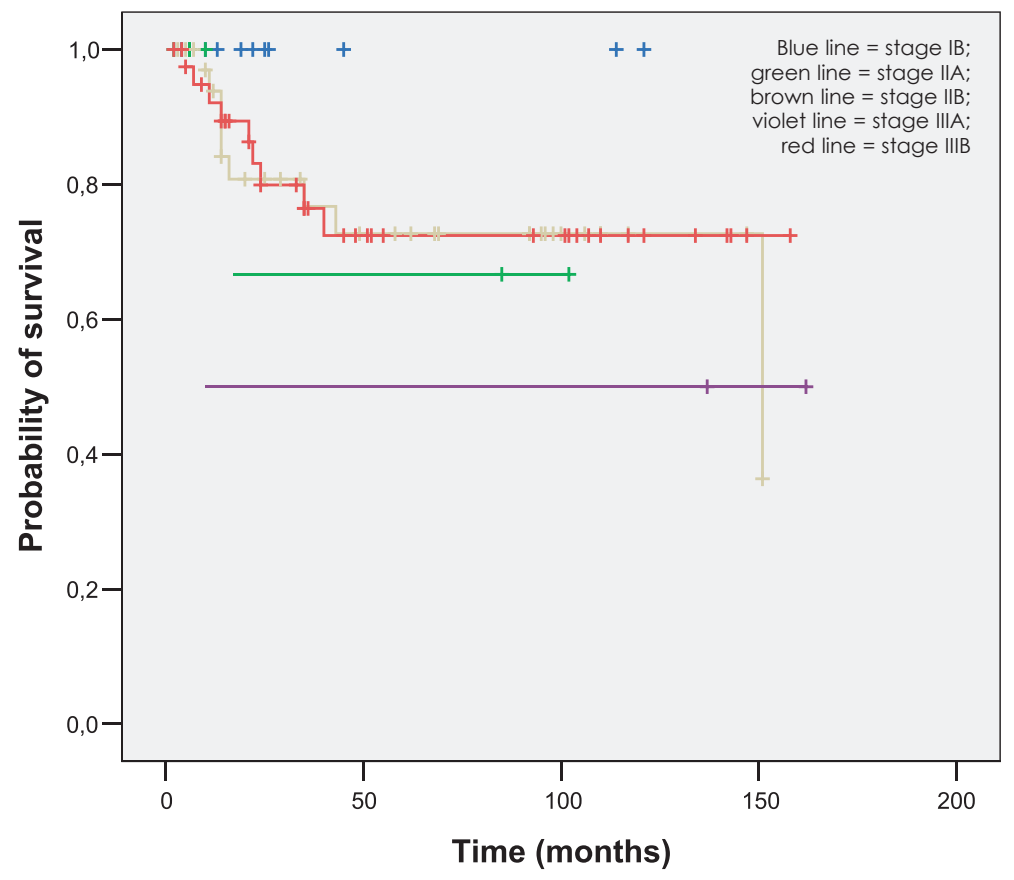

FIGURE 4. Local control according to FIGO stage.

sion of the disease in the vagina and poor coverage of the primary tumour with the standard applicator at BT. This could have resulted in lower DSS and OS rates as it would be expected for these two stages. ${ }^{33-39}$ Also the number of patients in both stages (seven in stage IIA, four in stage IIIA) was not big enough to make any definite conclusions.

LC rate in stage IIIB group, also the largest group of patients, was very good $(72.4 \%)$. The Vienna group reported $69.1 \%$ LC rate at three years, while Ferrigno et al. reported $62 \%$ in stage II and III patients and $58 \%$ in stage III at five years. ${ }^{35,40,41}$ In the study of Barillot et al. the incidence of local failure at five years in stage IIIB was $48.5 \%{ }^{39}$ The possible reason for high LC in stage IIIB and low LC rate in other stages (IIA and IIIA) can be explained by the lack of diagnostic procedures (CT and MRI) used to determine TNM stage.

Point A dose showed to be an important factor determining not only $\mathrm{LC}$ rate but also OS rate. If the dose was lower than $65 \mathrm{~Gy}$, the 5-year survival rate was $32.2 \%$ and LC rate $59.8 \%$, on the other hand if the dose was equal or higher than $65 \mathrm{~Gy}$, OS was $55.1 \%$ and LC rate as high as $89.2 \%$. A rather high LC rate can be partly explained by the lack of stage IVA patients in the study. The Vienna group reported on OS and pelvic control rate at three years of $40 \%$ and $60 \%$ for stage IVA, and of $58.2 \%$ and $77.6 \%$ for all patients, respectively. ${ }^{35}$ Perez et al. included 20 patients in stage IVA disease. There were 


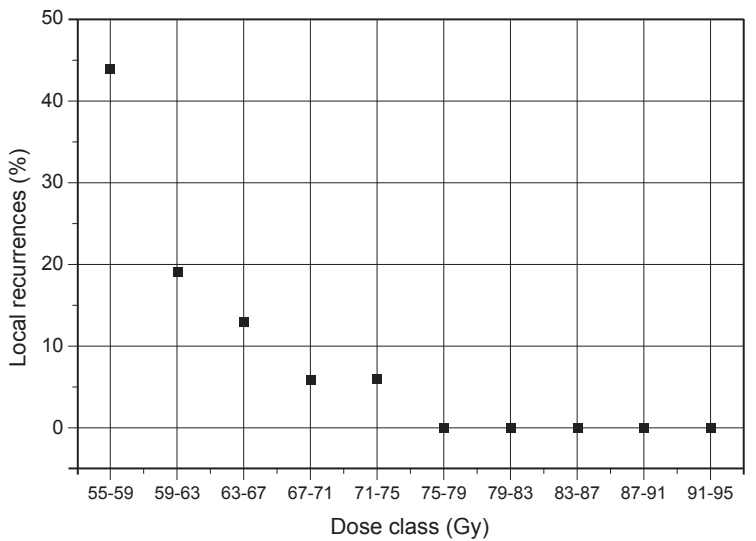

FIGURE 5. Proportion of local recurrences as a function of the point A dose. Point A dose is divided in ten dose classes with a class interval of $4 \mathrm{~Gy}$.

no-long term survivors among them. The overall incidence of pelvic recurrences in stage IVA was $72 \%$, and of distant metastases $55 \%$, respectively. ${ }^{38}$ Barillot et al. reported 5-year OS rate of $23 \%$ and local failure rate of $100 \%$ in stage IV, and of $68 \%$ in all stages, respectively. ${ }^{39}$

Dose is an important factor for the tumour cure. The optimal dose for the tumour is balanced with the dose to critical organs - sigmoid colon, rectum and bladder. The mean dose to point $\mathrm{A}$ in our patients was $66.5 \mathrm{~Gy}$, while the mean dose to organs at risk was below our departmental constraints. Gastrointestinal late toxicities developed in 15.3\%, $6.1 \%$ were grade 3 and 4 late reactions. Probability of grade three and four late side effects in the first five years was $7.1 \%$ for gastrointestinal tract. This is comparable with the Vienna group, which reported the incidence of $6.1 \%$ at three years. ${ }^{35}$ Lorvidhaya reported $7 \%$ combined grade 3 and 4 late complication rate for bowel and bladder. ${ }^{42}$ Based on our own experience with MRI based planning in BT and according to the literature, the dose to the rectum (D2cc) is usually lower than the dose to other critical organs. ${ }^{12,13,27,43,44}$ Most of the published series report a higher dose to the sigmoid colon than to the rectum. In other words, late gastrointestinal toxicities could be mainly correlated to the high dose to the sigmoid colon rather than to the dose to the rectum. ${ }^{45}$ In historical cases the dose to the sigmoid was not registered, so the correlation between the dose to the rectum and late toxicities is not straightforward. However, many studies that compared ICRU doses to critical organs and dose-volume histogram parameters (D2cc) proved a good correlation between ICRU dose and D2cc, especially for the rectal ICRU dose. ${ }^{46-49}$
Serious late bladder complications (grade 3 and 4) were rather rare and reported only in $2 \%$ of patients. Vaginal late toxicities grade 3 and 4 were also not as common as reported in the literature, probably because they were not systematically and prospectively recorded..$^{50}$ Vaginal late side effects are not commonly reported in the literature..$^{39,42}$ The Vienna group is one of the few who provide data on vaginal morbidity after definitive radiotherapy. They reported a $30.6 \%$ grade 3 and 4 vaginal complication rate. ${ }^{35}$

Fifteen out of 27 patients with recurrent disease developed relapse at distant sites. One of the reasons for a big proportion of distant failures could be, that CT/MRI were not yet systematically used in uterine cervix cancer patients at that time and only a minority of patients $(6 \%)$ received concurrent chemotherapy with EBRT. The causes for omitting chemotherapy were advanced age, hydronephrosis, afunction/hypofunction of one or both kidneys, raised creatinin level and other comorbidities. A more systematic introduction of concurrent chemotherapy at our Institute started only after the year $2000 .{ }^{1}$ It can be speculated that with the more wide implementation of sensitizing chemotherapy into the primary treatment of advanced disease distant failures can be further reduced and the survival improved. ${ }^{50-53}$ Histology, point A dose and presence of positive lymph nodes proved to be critical factors that affect prognosis. Other variables such as age, grade, stage, overall treatment time and tumour size also influenced the survival and LC in other studies. ${ }^{38,39,54}$ Their relevance was not confirmed in our study. The tumour size was not tested as the covariate in this study because it was not systematically monitored.

\section{Conclusions}

Results of the combined treatment (conventional 2D EBRT + LDR BT) of uterine cervix cancer at the Institute of Oncology Ljubljana were evaluated. 2D based BT approach was associated with good rates of LC in stage IIIB disease, which was the largest group in our study. Variables, influencing prognosis were histology, point A dose and lymph node status. Improved LC and reduced morbidity rates may be expected in the era of the systematic implementation of MRI-based adaptive BT at our department. Treatment results could be further improved with the development of new (individually tailored) applicators to enable the adequate dosecoverage of advanced tumours. 


\section{References}

1. Morris M, Eifel PJ, Lu J, Grigsby PW, Levenback C, Stevens RE, et al. Pelvic radiation with concurrent chemotherapy compared with pelvic and para-aortic radiation for high-risk cervical cancer. N Engl J Med 1999; 340: 1137-43.

2. Keys HM, Bundy BN, Stehman FB, Mudersprach LI, Chafe WE, Suggs CL 3rd et al. Cisplatin, radiation, and adjuvant hysterectomy for bulky stage IB cervical carcinoma. N Engl J Med 1999; 340: 1154-61.

3. Whitney CW, Sause W, Bundy BN, Malfetano JH, Hannigan EV, Fowler WC Jr, et al. Randomized comparison of fluorouracil plus cisplatin versus hydroxyurea as an adjunct to radiation therapy in stage IIB-IVA carcinoma of the cervix with negative para-aortic lymph nodes: a Gynecologic Oncology Group and Southwest Oncology Group study. J Clin Oncol 1999; 17: 1339-48.

4. Green JA, Kirwan JM, Tierney JF, Symonds P, Fresco L, Collingwood M, et al. Survival and recurrence after concomitant chemotherapy and radiotherapy for cancer of the uterine cervix: a systematic review and meta-analysis. Lancet 2001; 8: 358(9284): 781-6.

5. Vale C. Reducing uncertainties about the effects of chemoradiotherapy for cervical cancer: A systematic review and meta-analysis of individual patient data from 18 randomized trials. J Clin Oncol 2008; 26: 5802-12.

6. Gerbaulet A, Pötter R, Haie-Meder C. Cervix cancer. In: Gerbaulet A, Pötter $\mathrm{R}$, Haie-Meder C, editors. The GEC ESTRO handbook of brachytherapy. Brussels: ESTRO; 2002. p. 301-63.

7. Pötter R, Van Limbergen E, Wambersie A. Reporting in brachytherapy: dose and volume specification. In: Gerbaulet A, Pötter R, Mazeron JJ, Meertens $\mathrm{H}$, Van Limbergen E, editors. The GEC ESTRO handbook of brachytherapy. Brussels: ESTRO; 2002. p. 155-215.

8. ICRU, International Commission of Radiation Units and Measurements. Dose and volume specification for reporting intracavitary therapy in gynaecology. ICRU Report 38. Bethesda, MD: ICRU; 1985.

9. Massey JB, Pointon RS, Wilkinson JM. The Manchester System and the BCRU recommendations for brachytherapy source specification. BrJ Radiol 1985; 58: 911-3.

10. Guedea F, Ellison T, Venselaar J, Borras JP, Hoskin P, Poetter R, et al. Overview of brachytherapy resources in Europe: a survey of patterns of care study for brachytherapy in Europe. Radiother Oncol 2007; 82: 50-4.

11. Guedea F, Ellison T, Hoskin P, Hellebust TP, Didier Peiffert D, Londres B, et al. Patterns of care of brachytherapy in Europe: updated results. Radiother Oncol 2010; 97: 514-20.

12. Haie-Meder C, Pötter R, Van Limbergen E, Briot E, De Brabandere M, Dimopoulos J, et al. Recommendations from Gynaecological (GYN) GECESTRO Working Group (I): concepts and terms in 3D image based 3D treatment planning in cervix cancer brachytherapy with emphasis on MRI assessment of GTV and CTV. Radiother Oncol 2005; 74: 235-45.

13. Pötter R, Haie-Meder C, Van Limbergen E, Briot E, De Brabandere $M$ Dimopoulos J, et al. Recommendations from gynaecological (GYN) GEC ESTRO working group (II): concepts and terms in 3D image-based treatment planning in cervix cancer brachytherapy-3D dose volume parameters and aspects of $3 \mathrm{D}$ image-based anatomy, radiation physics, radiobiology. Radiother Oncol 2006; 78: 67-77.

14. Wachter-Gerstner N, Wachter S, Reinstadler E, Fellner C, Knocke TH, Wambersie A, et al. Bladder and rectum dose defined from MRI based treatment planning for cervix cancer brachytherapy: comparison of dose-volume histograms for organ contours and organ wall, comparison with ICRU rectum and bladder reference point. Radiother Oncol 2003; 68: 269-76.

15. Pötter R, VanLimbergen E, Gerstner N, Wambersie A. Survey of the use of the ICRU 38 in recording and reporting cervical cancer brachytherapy. Radiother Oncol 2001; 58: 11-8.

16. Pötter R. Modern imaging in brachytherapy. In: Gerbaulet A, Pötter R, Mazeron JJ, Meertens $\mathrm{H}$, Van Limbergen E, editors. The GEC ESTRO handbook of brachytherapy. Brussels: ESTRO; 2002. p. 123-51.

17. Barillot I, Horiot JC, Maingon P, Truc G, Chaplain G, Comte J, et al. Impact on treatment outcome and late effects of customized treatment planning in cervix carcinomas: baseline results to compare new strategies. Int J Radiat Oncol Biol Phys 2000; 48: 189-200.

18. Perez CA, Grigsby PW, Lockett MA, Chao KS, Williamson J. Radiation therapy morbidity in carcinoma of the uterine cervix: dosimetric and clinical correlation. Int J Radiat Oncol Biol Phys 1999; 44: 855-66.
19. Kovalic JJ, Perez CA, Grigsby PW, Lockett MA. The effect of volume of disease in patients with carcinoma of the uterine cervix. Int J Radiat Oncol Biol Phys 1991; 21: 905-10.

20. Perez CA, Fox S, Lockett MA, Grigsby PW, Camel HM, Galakatos A, et al Impact of dose in outcome of irradiation alone in carcinoma of the uterine cervix: analysis of two different methods. Int J Radiat Oncol Biol Phys 1991; 21: 885-98.

21. Roeske JC, Mundt AJ, Halpern H, Sweeney P, Sutton H, Powers C, et al. Late rectal sequelae following definitive radiation therapy for carcinoma of the uterine cervix: A dosimetric analysis. Int I Radiat Oncol Biol Phys 1997; 37: $351-8$.

22. Chen SW, Liang JA, Yeh LS, Yang SN, Shiau AC, Lin FJ. Comparative study of reference points by dosimetric analyses for late complications after uniform external radiotherapy and high-dose-rate brachytherapy for cervical cancer. Int J Radiat Oncol Biol Phys 2004; 60: 663-71.

23. Ogino I, Kitamura T, Okamoto N, Yamasita K, Aikawa Y, Okajima H, et al. Late rectal complication following high dose rate intracavitary brachytherapy in cancer of the cervix. Int J Radiat Oncol Biol Phys 1995; 31: 725-34.

24. Ferrigno R, dos Santos Novaes PE, Pellizzon AC, Maia MA, Fogarolli RC, Gentil AC, et al. High-dose-rate brachytherapy in the treatment of uterine cervix cancer. Analysis of dose effectiveness and late complications. Int $J$ Radiat Oncol Biol Phys 2001; 50: 1123-35.

25. Kim HJ, Kim S, Ha SW, Wu HG. Are doses to ICRU reference points valuable for predicting late rectal and bladder morbidity after definitive radiotherapy in uterine cervix cancer? Tumori 2008; 94: 327-32.

26. Petric $P$, Hudej R, Marolt-Mušič M. MRI assisted cervix cancer brachytherapy pre-planning, based on insertion of the applicator in para-cervical anaesthesia: preliminary results of a prospective study. J Contemp Brachytherapy 2009; 1: 163-9.

27. Petric P, Hudej R, Rogelj P, Blas M, Segedin B, Zobec Logar HB, Dimopoulos JCA. Comparison of 3D MRI with high sampling efficiency and 2D multiplanar MRI for contouring in cervix cancer brachytherapy. Radiol Oncol 2012; 46: 242-51.

28. Cox JD, Stetz J, Pajak TF. Toxicity criteria of the Radiation Therapy Oncology Group (RTOG) and the European Organization for Research and Treatment of Cancer (EORTC). Int J Radiat Oncol Biol Phys 1995; 31: 1341-6.

29. LENT SOMA scales for all anatomic sites. Int J Radiat Oncol Biol Phys 1995; 31: 1049-91.

30. Baškovič $M$, Cerar $O$, Kaučič $M$, Kocijan $A$, Kovačič J, Kuhelj J, et al. [Guidelines for the treatment of the gynaecological malignancies]. [Slovenian]. Ljubljana: Zveza slovenskih društev za boj proti raku; 1992.

31. Baškovič M, Bebar S, Cerar O, Fras AP, Kragelj B, Robič V, et al. [Gynaecological malignancies. Guidelines for the treatment at the Institute of Oncology Ljubljana and Gynaecological Clinic of the University Medical Centre Ljubljana]. [Slovenian]. 2nd revisioned edition. Ljubljana: Zveza slovenskih društev za boj proti raku; 2001.

32. Stržinar $V$, Baškovič $M$, Bebar $S$, Cerar $O$, Fras $A P$, Koritnik $K$, et al. [Gynaecological malignancies. Guidelines for the treatment at the Institute of Oncology Ljubljana and Gynaecological Clinic of the University Medical Centre Ljubljana]. [Slovenian]. 3rd revisioned edition. Ljubljana: Zveza slovenskih društev za boj proti raku, 2002.

33. Perez Ca, Breaux S, Bedwinek JM, Madoc-Jones H, Camel HM, Purdy JA, et al. Radiation therapy alone in the treatment of carcinoma of the uterine cervix. II. Analysis of complications. Cancer 1984; 54: 235-46.

34. Fletcher GH, Hamburger AD. Female pelvis. Squamous cel carcinoma of the uterine cervix. In: Fletcher GH, editor. Textbook of radiotherapy. 3rd edition. Philadelphia: Lea and Febiger; 1980. p. 720-89.

35. Pötter R, Knocke TH, Fellner C, Baldass M, Reinthaller A, Kucera H. Definitive radiotherapy based on HDR brachytherapy with iridium 192 in uterine cervix carcinoma: report on the Vienna University Hospital findings (19931997) compared to the preceding period in the context of ICRU 38 recommendations. Cancer Radiother 2000; 4: 159-72.

36. Horiot JC, Pigneux J, Pourquier H. Radiotherapy alone in carcinoma of the intact uterine cervix according to G. H. Fletcher guidelines: a French cooperative study of 1383 cases. Int J Radiat Oncol Biol Phys 1988; 14: 605-11.

37. Pernot M, Hoffstetter S, Peiffert D, Carolus JM, Guillemin F, Verhaeghe JL et al. Statistical study of a series of 672 cases of carcinoma of the uterine cervix. Results and complications according to age and modalities of treatment. Bull Cancer 1995; 82: 568-81. 
38. Perez CA, Grigsby PW, Chao KS, Mutch DG, Lockett MA. Tumor size, irradiation dose, and long-term outcome of carcinoma of uterine cervix. Int Radiat Oncol Biol Phys 1998; 41: 307-17. Erratum in: Int J Radiat Oncol Biol Phys 1999; 45: 1093.

39. Barillot I, Horiot JC, Pigneux J, Schraub S, Pourquier H, Daly N, et al. Carcinoma of the intact uterine cervix treated with radiotherapy alone: French cooperative study: update and multivariate analysis of prognostics factors. Int J Radiat Oncol Biol Phys 1997; 38: 969-78.

40. Ferrigno R, dos Santos Novaes PE, Pellizzon AC, Maia MA, Fogarolli RC, Gentil AC, et al. High-dose brachytherapy in the treatment of uterine cervix cancer. Analysis of dose effectiveness and late complications. Int J Radiat Oncol Biol Phys 2001; 50: 1123-35.

41. Ferrigno R, Campos de Oliveira Faria SL, Weltman E, Salvajoli JV, Segreto RA Pastore A, et al. Radiotherapy alone in the treatment of uterine cervix cancer with telecobalt and low-dose-rate brachytherapy: retrospective analysis of results and variables. Int J Radiat Oncol Biol Phys 2003; 55: 695-706.

42. Lorvidhaya V, Tonusin A, Changwiwit W, Chitapanarux I, Srisomboon J, Wanwilairat $S$, et al. High-dose-rate afterloading brachytherapy in carcinoma of the cervix: an experience of 1992 patients. Int J Radiat Oncol Biol Phys 2000; 46: 1185-91.

43. Dimopolus J, Schard G, Berger D, Lang S, Goldner G, Helbich T, et al. Systematic evaluation of MRI findings in different stages of treatment of cervical cancer: potential of MRI on delineation of target, patho-anatomical structures and organs at risk. Int J Radiat Oncol Biol Phys 2006; 64: 1380-8.

44. Kirisits C, Lang S, Dimopoulos J, Berger D, Georg D, Pötter R. The Vienna applicator for combined intracavitary and interstitial brachytherapy of cervical cancer: Design, application, treatment planning, and dosimetric results. Int J Radiat Oncol Biol Phys 2006; 65: 624-30.

45. Erickson B, Grossheim L, Mai J. Imaging the nondisplaced rectosigmoid during HDR brachytherapy for cervical cancer can alter dose specification. [Abstract]. Radiother Oncology 2004; 71(Suppl 2): S9.

46. Pelloski CE, Palmer M, Chronowski GM, Jhingran A, Horton J, Eifel PJ. Comparison between CT-based volumetric calculations and ICRU referencepoint estimates of radiation doses delivered to bladder and rectum during itracavitary radiotherapy for cervical cancer. Int I Radiat Oncol Biol Phys 2005; 62: 131-7.

47. Kirisits C, Pötter R, Lang S, Dimopoulos J, Wachter-Gerstner N, Georg D. Dose and volume parameters for MRI-based treatment planning in intracavitary brachytherapy for cervical cancer. Int J Radiat Oncol Biol Phys 2005 62: 901-11.

48. Datta NR, Srivastava A, Maria Das KJ, Gupta A, Rastogi N. Comparative assessment of doses to tumor, rectum, and bladder as evaluated by orthogonal radiographs vs. computer enhanced computed tomography-based intracavitary brachytherapy in cervical cancer. Brachytherapy 2006; 5: 223-9.

49. Cheng JC, Peng LC, Chen YH, Huang DY, Wu JK, Jian JJ. Unique role of proximal rectal dose in late rectal complications for patients with cervical cance undergoing high-dose-rate intracavitary brachytherapy. Int J Radiat Oncol Biol Phys 2003; 57: 1010-8.

50. Morris M, Eifel PJ, Lu J, Grigsby P, Levenback C, Stevens RE, et al. Pelvic radiation with concurrent chemotherapy compared with pelvic and para-aortic radiation for high-risk cervical cancer. New Engl J Med 1999; 340: 1137-43.

51. Haie-Meder C, de Crevoisier R, Bruna A, Lhommé C, Pautier P, Morice P, et al. Concomitant chemoradiation in patients with cervix cancer. Bull Cancer 2005; 92: 1032-8.

52. Heinzelmann F, Henke G, von Grafenstein M, Weidner M, Paulsen F, Staebler $A$, et al. Adjuvant radiochemotherapy in patients with locally advanced highrisk cervical cancer. Strahlenther Onkol 2012; 188: 568-75.

53. Kim JY, Kim JY, Kim JH, Yoon MS, Kim J, Kim YS. Curative chemoradiotherapy in patients with stage IVB cervical cancer presenting with paraortic and left supraclavicular lymph node metastases. Int J Radiat Oncol Biol Phys 2012; 84: $741-7$

54. Perez CA, Grigsby PW, Castro-Vita H, Lockett MA. Carcinoma of the uterine cervix. I. Impact of prolongation of overall treatment time and timing of brachytherapy on outcome of radiation therapy. Int J Radiat Oncol Biol Phys 1995; 32: 1275-88. 